удК 338.439

С. Ю. Дёмин

Байкальский государственный университет, г. Иркутск, Российская Федерация

\title{
РОЛЬ ИМПОРТОЗАМЕЩЕНИЯ В ОБЕСПЕЧЕНИИ ПРОДОВОЛЬСТВЕННОЙ БЕЗОПАСНОСТИ В РОССИИ
}

\begin{abstract}
АНнОтАЦИЯ. В статье рассматривается проблема продовольственной безопасности как основной составляющей экономической и национальной безопасности страны. Охарактеризованы критерии продовольственной безопасности и проведен анализ современного состояния рынка продовольствия по основным продуктам питания. Анализируются особенности сельского хозяйства России, влияющие на обеспечение продовольственной безопасности. Рассматривается структура производства основных продуктов питания в стране и ее взаимосвязь с импортом и экспортом. Приведены критерии оценки состояния продовольственной безопасности и направления развития сельскохозяйственного производства. Определены возможные угрозы для продовольственной безопасности страны. Обобщается опыт других стран в преодолении возможных проблем обеспечения продовольственной безопасности. Предлагаются рекомендации по устранению возможных угроз обеспеченности населения продовольствием и пути решения проблем, связанных с обеспечением продовольственной безопасности России.

КЛЮЧЕВЫЕ СЛОВА. Продовольственная безопасность; продовольствие; импорт продуктов; сельскохозяйственная продукция; продукты питания отечественного производства; Доктрина продовольственной безопасности.

ИНФОРМАЦИЯ О СТАТЬЕ. Дата поступления 30 декабря 2015 г.; дата принятия к печати 25 января 2016 г.; дата онлайн-размещения 31 марта 2016 г.
\end{abstract}

S. Yu. Demin

Baikal State University,

Irkutsk, Russian Federation

\section{ROLE OF IMPORT SUBSTITUTION IN PROVIDING FOOD SECURITY IN RUSSIA}

\begin{abstract}
The article considers problems of food security as a main consistent of food security of economic and national security of the country. It characterizes the criteria of food security and carries out an analysis of the current food market state. It gives an analysis of the features of Russia's agriculture that impact on providing food security, considers the structure of basic foodstuff production and its interrelation with import and export. It presents the criteria of assessing the food security situation and directions of developing the agricultural production, as well as identifies possible threats for the country's food security. The article generalizes the experience of other countries in overcoming possible problems of providing food security. It offers recommendations on eliminating possible threats in providing the population with food and ways of solving problems associated with provision of Russia's food security.
\end{abstract}

KEYWORDS. Food security; food; foodstuff import; agricultural product; foodstuff of domestic production; Food security Doctrine.

ARTICLE INFO. Received December 30, 2015; accepted January 25, 2016; available online March 31, 2016.

Продовольственная безопасность является важнейшей частью экономической и национальной безопасности государства. При оценке обеспеченности продовольствием в качестве критерия продовольственной независимости в мировой практике используется уровень поставок импортного продовольствия в размере 30 \% общих объемов его

() С. Ю. Дёмин, 2016

\section{Baikal Research Journal}


потребления в стране, поскольку при прочих равных условиях превышение указанного уровня порождает стратегическую зависимость государства от других стран [1].

Определение национальной безопасности основывается на различных показателях, включая существующий уровень потребления продовольствия на душу населения и коэффициент самообеспеченности страны. Индекс продовольственной безопасности хотя и показывает степень уязвимости страны, но не дает полного представления о действительном уровне обеспечения населения продовольствием.

Аграрный сектор, сельское хозяйство в экономике любой страны занимают особое место. Производство продуктов питания, как основа жизнедеятельности людей и воспроизводства рабочей силы, производство сырья для многих видов непроизводственных потребительских товаров и продуктов производственного значения обуславливают специфичность роли, отведенной сельскому хозяйству. Из этого следует, что уровень развития сельского хозяйства во многом определяет уровень экономической и продовольственной безопасности страны [2]. В современном мире наряду с энергетическими сложностями, вызванными ростом потребления энергоресурсов на производственные и социальные нужды, следствием чего явилось их многократное удорожание, особенно нефти, периодически повторяющимися финансовыми кризисами, прибавилась еще одна серьезная проблема - продовольственная. В ряде стран вопросы продовольствия обострились до предела. Анализ сложившегося положения в России свидетельствует о том, что нам потенциально грозит и то, и другое [3].

Значимость данной проблемы определяется прежде всего тем, что в структуре потребностей человека потребность в пище относится к первой группе, а степень ее удовлетворения недостаточна. Кроме того, из-за тесной связи производства продовольствия и природной среды неэкологическое сельское хозяйство может привести к возникновению опасных факторов, влекущих за собой процессы, связанные с уменьшением количества и ухудшением качества природных ресурсов, от которых прямо или косвенно зависит производство продовольствия, а, следовательно, и продовольственная безопасность [4]. Как показывают данные проведенных сравнений, производительность труда в сельском хозяйстве России, чем в развитых странах Запада (в первую очередь, США), значительно ниже. Причиной тому является целый ряд специфических особенностей сельского хозяйства России. Во-первых, аграрный сектор в развитых странах представляет собой классический пример совершенно конкурентной отрасли. Сельскохозяйственное производство ведется большим числом продавцов, каждый из которых не может повлиять на цены, поскольку продукты практически не диверсифицируемы. Соответственно, отсутствует преграды входа и выхода на рынок. Во-вторых, условия деятельности сельхозтоваропроизводителей в России и за рубежом являются практически несопоставимыми, прежде всего, с точки зрения климатических условий. Засухи, наводнения, болезни животных и растений делают аграрный сектор относительно рискованным для вложения капитала. И, в-третьих, вследствие слабой дифференцируемости продукции продавцы не имеют достаточных возможностей для повышения цен. Как известно, паритет цен на продукцию сельскохозяйственного производства и средства производства для аграрного сектора из года в год во всем мире изменяется не в его пользу. Укрепление продовольственной безопасности на национальном и региональном уровнях - обязательное, но недостаточное условие для обеспечения продовольствием людей. Существенное сокращение потребления продовольствия значительной частью населения - серьезный индикатор снижения качества жизни жителей России и прямая угроза ее экономической независимости.

Данная ситуация, угрожающая продовольственной безопасности РФ, возникла в результате ошибочных предпосылок аграрных реформ, проводившихся в стране. Однако по картофелю за все анализируемые годы у России была полная самообе-

\section{Baikal Research Journal}

электронный научный журнал Байкальского государственного университета 
спеченность. По мясу и мясопродуктам в начале 90 -х гг. ХХ в. самообеспеченность была выше порогового уровня (критерий - 85 \%), затем она снизилась до 60,6 \% в 1997 г. Характерно, что квоты на импортное мясо год от года растут при снижении таможенной пошлины на поставки сверх квоты [5].

Быстрый рост независимости по мясу начался с осуществления приоритетного национального проекта по развитию агропромышленного комплекса. В 2012 г. уровень независимости по мясу составлял уже 75,9 \%, т. е. был ниже порогового уровня на $9,1 \%$. Вместе с тем по отдельным видам мясной продукции продовольственная безопасность существенно различается. По мясу птицы пороговый уровень в 2012 г. был превышен $(86,6$ \% ), по свинине он существенно ниже порогового уровня $(63,2 \%)$, а по говядине составлял лишь 37,7 \% . Снижение объемов производства связывается сегодня не только с перечисленными процессами, но и с непродуманной трансформацией форм собственности на землю и изменением форм хозяйствования. Потеряли свою значимость организационные структуры управления сельским хозяйством, обслуживающими и перерабатывающими предприятиями. Сельское хозяйство оказалось в тисках между объективно ограниченным платежеспособным спросом, монополизмом сфер переработки и торговли и монополиями, поставляющими ему ресурсы.

Для подъема сельского хозяйства сегодня нужен государственный протекционизм, связанный с бюджетным финансированием важнейших целевых программ (направленных на повышение плодородия земель, развитие социальной и производственной инфраструктуры сельских поселений). Необходимо стимулирование отечественных производителей через использование федеральных и региональных заказов, предоставление налоговых льгот предприятиям торговли и переработки, закупающим отечественную продукцию, совершенствование кредитования и финансирования агропромышленного комплекса.

Развитие аграрного сектора оказывает стабилизирующее действие на всю макроэкономическую ситуацию. Это происходит при условии медленного роста цен на продукцию сельского хозяйства.

В условиях кризиса ни одна страна мира не смогла обеспечить выход из него на чисто рыночной основе. Слишком много нестабильных факторов. В данном вопросе наиболее разумным было бы обратиться к опыту развитых стран. При рассмотрении дел в производстве продовольствия в западных странах можно выделить примерно следующие моменты:

1. Сельское хозяйство и продовольственный рынок не являются саморегулирующимися. Это объясняется тем, что спрос на продовольствие как на товар первой необходимости характеризуется низкой эластичностью, которая свойственна и сельскому хозяйству как отрасли весьма консервативной. В то же время цены на рынке продовольствия чрезвычайно эластичны и склонны к большим колебаниям, поэтому необходимо государственное воздействие на цены агропродукции, иначе последние из-за высокой эластичности начинают играть разрушительную роль по отношению и к потребителю, и к производителю.

2. В современных концепциях ценообразования на сельскохозяйственную продукцию в странах с развитой экономикой предусматривается активное государственное вмешательство в формирование цен, их регулирование. Государство устанавливает лимиты цен, производит дотации и компенсации, но цены от этого не перестают быть важным рыночным инструментом. Происходит это потому, что они отрегулированы на рынке путем спроса и предложения. В рыночных условиях государство должно проводить политику активного воздействия на функционирование продовольственного рынка, создавая экономические предпосылки для развития сельскохозяйственного производства в нужных объемах и пропорциях. Государство компенсирует сель-

\section{Baikal Research Journal}

электронный научный журнал Байкальского государственного университета 
скохозяйственным товаропроизводителям отклонение от рыночной цены в размерах, необходимых для их деятельности при заданном уровне доходности.

3. В развитых странах проводится мониторинг и регулирование цен на сельхозпродукцию, организовано слежение за динамикой ряда экономических показателей.

Либерализация цен в России и сопровождавшая ее гиперинфляция привели предприятия агропромышленного комплекса к моментальной утрате собственных оборотных средств и многократно усилили диспаритет цен. Концепция продовольственной безопасности на национальном уровне не означает самообеспечение населения страны продовольствием, она предполагает, что страна должна производить достаточно продуктов для собственных нужд, но, если сравнительные преимущества не способствуют этому, она должна быть в состоянии импортировать необходимое количество продовольствия.

Однако есть принципы разумной достаточности. Сейчас объем импорта продовольствия в Россию равен 22-26 млрд дол. Столь высокий уровень импорта продовольствия несет определенные угрозы продовольственной безопасности страны. Они обусловлены прежде всего ущербом, наносимым отечественным производителям продовольствия и сельскохозяйственного сырья. Этот ущерб может быть выражен через систему более или менее конкретных показателей и критериев. Во-первых, речь идет о прямом вытеснении отечественных сельхозпроизводителей с внутреннего продовольственного рынка, сужении рынка сбыта их продукции и лишении их потенциальных дополнительных доходов от ее реализации. Во-вторых, ухудшаются практически все показатели деятельности сельскохозяйственных предприятий, рекомендуемые, в частности, соглашением по защитным мерам Всемирной торговой организации для оценки ущерба, который несет отрасль национальной экономики вследствие возросшего импорта соответствующего товара (группы товаров). К таким показателям относятся темпы роста импорта данного товара в абсолютных и относительных величинах, доля возрастания импорта на национальном рынке, изменения в уровнях продаж, производства, производительности, загрузки мощностей, доходов и потерь, занятости. В-третьих, подорван производственно-финансовый потенциал сельского хозяйства и истощены естественные факторы сельского хозяйства, причем истощение грозит принять необратимый характер. В-четвертых, в связи с укреплением позиций зарубежных производителей на отечественном продовольственном рынке Россия превращается в регион сбыта недоброкачественной, с истекшими сроками хранения продукции. Угрозы продовольственному самообеспечению населения страны следует связывать прежде всего с импортом продуктов питания, с политикой внешнеэкономической деятельности. В последнее время правительства западных государств проявляют особый интерес к российской экономике. Научными структурами и спецслужбами этих стран разработаны «индикаторы чувствительности», с ориентацией на которые принимаются соответствующие тактические и стратегические решения. Индикаторы ранжированы в такой последовательности:

- стабильность социально-политической ситуации и ее возможное изменение в долгосрочной и среднесрочной перспективе;

- уровень управленческой деятельности правительства и возможность ухода его в отставку (даются варианты тех, кто может прийти на смену);

- уровень компетентности директорского корпуса;

- характеристика официальной оппозиции;

- характеристика нелегальной оппозиции;

- тенденции в экономической политике правительства страны, отношение представителей ветвей власти к зарубежному капиталу;

- риск национализации капитала и возможные варианты его компенсации; уровень коррумпированности высших руководителей;

\section{Baikal Research Journal}


- степень государственного вмешательства в экономику, удельный вес государственной собственности (не следует обольщаться по поводу выделения иностранных кредитов без целевого их использования в стране с учетом интересов иностранного бизнеса) [6].

Вызывает большую озабоченность подконтрольность значительной части крупнейших производителей сельхозпродукции и продовольствия иностранным юридическим лицам. Так, в 5 из 10 крупнейших производителей сельхозпродукции в число собственников прямо или через ряд юридических лиц входят компании, зарегистрированные за рубежом (пакеты акций от 36 до 99 \%). У 5 крупнейших производителей сахара (общий объем производства - более 60 \% от производства в стране) контрольными пакетами владеют компании, зарегистрированные за рубежом. Выявление масштабов этого явления и его природы позволит предотвратить риски в части замораживания счетов компаний, сокращения производства в критических ситуациях. В этой связи и в России целесообразно выявить масштабы явления, сформировать осознанную политику в отношении крупных землевладений, в том числе в руках иностранных лиц [7].

Продовольственную безопасность России нельзя рассматривать с позиции двух крайностей - 100 \% самообеспечения и неограниченного ввоза продовольствия. Прежде всего, необходимо восстановить сельскохозяйственное машиностроение и оснастить отрасль современной техникой. Производство многих видов техники вообще приостановлено.

Российская Федерация весь этот период времени выступала нетто-импортером продовольствия, занимая в данной сфере 4,5-5,2 \% мирового рынка (табл. 1).

Экспорт-илпорт продовольствия в России за 2000-2012 г.

\begin{tabular}{|c|r|r|r|}
\hline Год & $\begin{array}{c}\text { Экспорт продовольствия, } \\
\text { млрд дол. (\% общего экспорта) }\end{array}$ & $\begin{array}{c}\text { Импорт продовольствия, } \\
\text { млрд дол. (\% общего импорта) }\end{array}$ & $\begin{array}{c}\text { Баланс, } \\
\text { млрд дол. }\end{array}$ \\
\hline 2000 & $1,623(1,6)$ & $7,384(21,8)$ & $-5,761$ \\
\hline 2001 & $1,887(1,9)$ & $9,205(22,0)$ & $-7,318$ \\
\hline 2002 & $2,801(2,6)$ & $10,380(22,5)$ & $-7,579$ \\
\hline 2003 & $3,411(2,5)$ & $12,043(21,0)$ & $-8,632$ \\
\hline 2004 & $3,292(1,8)$ & $13,854(18,3)$ & $-10,562$ \\
\hline 2005 & $4,492(1,9)$ & $17,430(17,7)$ & $-12,938$ \\
\hline 2006 & $5,514(1,8)$ & $21,640(15,7)$ & $-16,126$ \\
\hline 2007 & $9,090(2,6)$ & $27,626(13,8)$ & $-18,536$ \\
\hline 2008 & $9,278(2,0)$ & $35,189(13,2)$ & $-25,911$ \\
\hline 2009 & $9,967(3,3)$ & $30,015(17,9)$ & $-20,048$ \\
\hline 2010 & $9,365(2,3)$ & $36,482(15,9)$ & $-27,117$ \\
\hline 2011 & $11,964(2,3)$ & $42,476(13,9)$ & $-30,512$ \\
\hline 2012 & $16,343(2,8)$ & $40,139(11,9)$ & $-23,796$ \\
\hline Итого & - & & $-214,836$ \\
\hline
\end{tabular}

Составлено по: Россия 2012: стат. справ. М.: Росстат, 2012. 59 с.

Таким образом, за 2000-2012 гг. Россия потеряла почти 215 млрд дол. Эту сумму нельзя назвать достаточно большой, но она является весьма существенной, особенно в сравнении с данными собственного сельскохозяйственного производства России (табл. 2).

В данной связи стоит подчеркнуть, что наполнение внутреннего рынка зарубежными поставками на 20 \% и более принято считать пороговым уровнем, критическим для продовольственной независимости, а следовательно, и для продовольственной безопасности страны в целом.

\section{Baikal Research Journal}


Таблица 2

Собственное производство сельскохозяйственной продукиии

\begin{tabular}{|c|r|r|r|}
\hline Год & $\begin{array}{c}\text { Импорт продовольствия, } \\
\text { млрд дол. }\end{array}$ & $\begin{array}{c}\text { Собственное производство, } \\
\text { млрд дол. }\end{array}$ & $\begin{array}{c}\text { Доля импорта, } \\
\text { \% на внутреннем рынке }\end{array}$ \\
\hline 2005 & 17,430 & 48,832 & $35,69(28,21)$ \\
\hline 2006 & 21,640 & 57,762 & $37,46(29,28)$ \\
\hline 2007 & 27,626 & 74,840 & $36,91(29,59)$ \\
\hline 2008 & 35,189 & 99,047 & $35,52(28,16)$ \\
\hline 2009 & 30,015 & 79,267 & $37,87(30,22)$ \\
\hline 2010 & 36,482 & 85,137 & $42,85(32,50)$ \\
\hline 2011 & 42,476 & 111,131 & $38,22(29,99)$ \\
\hline 2012 & 40,139 & 102,685 & $39,09(31,74)$ \\
\hline
\end{tabular}

Составлено по: Россия в цифрах. 2012: крат. стат. сб. М.: Росстат, 2012.573 с.

На самом деле все висит на волоске. Достаточно нашим западным контрагентам по той или иной причине всего на месяц-другой перекрыть поставки продовольствия в Россию, а Федеральной резервной системе США заморозить российские валютные активы - как дело будет сделано: мы со своими двухмесячными импортными продовольственными запасами получим дефицит продовольствия в стране.

Все приведенные цифры указывают как на значительный потенциал аграрного производства в России, так и на абсолютно неудовлетворительный характер его использования в рамках действующего варианта динамической модели обеспечения ее продовольственной безопасности, который условно можно обозначить как «нефть в обмен на продовольствие».

Данный вариант нельзя признать соответствующим требованиям продовольственной и национальной безопасности России, особенно на ближайшую перспективу, поскольку на нисходящем (кризисном) участке в ближайшее время будет происходить снижение стоимости энергоресурсов и рост стоимости продовольственных товаров. Это представляет существенную угрозу для действующей модели обеспечения России продовольствием, требуя существенного и быстрого роста сельскохозяйственного производства - прежде всего в тех сферах, где зависимость страны от внешней конъюнктуры критически высока, а именно - говядины и свинины, молочных продуктов, что, в свою очередь, невозможно без резкого увеличения производства фуражного и продовольственного зерна. В то же время сегодня значительная часть - по разным оценкам, от 40 до $45 \%$ отечественного зернового рынка находится под контролем иностранных компаний.

Аграрный сектор характеризуется еще и особым отношением общества к нему. Протекционизм, как экономическая политика защиты отечественного товаропроизводителя, присущ и сельскому хозяйству. Наряду с общими аргументами в пользу протекционизма (противодействия демпингу, защита становящейся отрасли, безработица и т. д.) в аграрной сфере используют и специфические доводы. В первую очередь - это стремление к продовольственной безопасности нации. Продовольственная безопасность является составной частью национальной безопасности страны, сохранение государственности и суверенитета России, важнейшей составляющей демографической политики, необходимым условиям реализации стратегического национального приоритета повышения качества жизни граждан на основе международных стандартов жизнеобеспечения.

К определению категории «продовольственная безопасность» существуют различные подходы, ориентирующиеся либо на импорт продуктов питания, либо на самообеспечение, либо на сочетание импорта и собственного производства продовольствия. Согласно наиболее распространенному в мире определению, продоволь-

\section{Baikal Research Journal}


ственная безопасность достигается путем обеспечения физического и экономического доступа к продовольствию [7]. В Доктрине продовольственной безопасности РФ подчеркивается, что «Продовольственная безопасность Российской Федерации состояние экономики страны, при котором обеспечивается продовольственная независимость Российской Федерации, гарантируется физическая и экономическая доступность для каждого гражданина страны пищевых продуктов, соответствующих требованиям законодательства Российской Федерации о техническом регулировании, в объемах не меньше рациональных норм потребления пищевых продуктов, необходимых для активного и здорового образа жизни" [8].

В настоящее время в России лишь небольшая доля населения имеет возможность питаться согласно медицинским нормам, рекомендованным Институтом питания PAMH, дифференцированным по возрасту, характеру работы, региональным особенностям и традициям. Анализ уровня доходов населения показал, что около 20 \% населения могут обеспечить для себя здоровый тип питания, примерно 17 \% населения страны хронически не доедают, а около 3 \% испытывают самый настоящий голод, поскольку их уровень доходов не позволяет нормально питаться. Доля расходов на питание россиян стабильно составляет $30-35 \%$ от всех потребительских расходов, а у $5 \%$ населения превышает $65 \%$, в то время как в США и в странах Евросоюза - 15-17\% . Это связано как с более низким уровнем доходов россиян сравнительно с американцами или европейцами, так и с более высокой стоимостью большинства продовольственных товаров на российском рынке. Оценку состояния продовольственной безопасности в сфере сельскохозяйственного производства и национальной конкурентоспособности предлагается проводить путем определения объемов производства сельскохозяйственной продукции, прогнозной продуктивности используемых в сельском хозяйстве земельных ресурсов. Для оценки состояния продовольственной безопасности в качестве критерия определяется удельный вес отечественной сельскохозяйственной, рыбной продукции и продовольствия в общем объеме товарных ресурсов (с учетом переходящих запасов) внутреннего рынка соответствующих продуктов, имеющих пороговые значения в отношении: зерна не менее $95 \%$, молока и молокопродуктов (в пересчете на молоко) - не менее $90 \%$, мяса и мясопродуктов - не менее 85 \% и т. д. ${ }^{1}$ По оценке Министерства сельского хозяйства России, по итогам 2012 г. показатели продовольственной безопасности Российской Федерации составили: по зерну - 98,9\% ; по сахару $-95,5 \%$; по маслу растительному - 84,2 \% ; по картофелю - 97,2 \% ; что выше порогового значения соответственно на 3,$9 ; 15,5 ; 4,2$ и $2,2 \%$.

Показатели продовольственной безопасности остаются в 2012 г. ниже пороговых значений, определенных в Доктрине продовольственной безопасности РФ: по мясу и мясопродуктам - на 10,4\% $(74,6 \%)$; по молоку и молокопродуктам - на $10,4 \%(79,6 \%)$; по рыбной продукции — на $1,8 \%$ (78,2 \% ) [9].

В конце 2013 г. министр сельского хозяйства РФ Н. Федоров сообщил, что Россия в 2013 г. почти достигла безопасного уровня производства мяса, прежде всего, за счет мяса птицы, следовательно, наблюдается положительная динамика. С одной стороны, с 2000 г. в России растет производство мяса, (особенно птицы), с другой стороны, около 30 \% мяса и мясопродуктов по-прежнему импортируется, экспорт незначителен.

Недостаток собственного производства, высокая зависимость по многим видам продовольствия от его импорта вызвали резкое повышение цен на внутреннем рынке. Необходимо отметить, что в настоящее время существенно возросла ори-

${ }^{1}$ Доктрина продовольственной безопасности РФ [Электронный pecypc]. URL: http://www.mc.ru/ documents/docu-ments/show/14857.19htm.

\section{Baikal Research Journal}

электронный научный журнал Байкальского государственного университета 
ентация товаропроизводителей, а вернее их посредников, на экспорт сельскохозяйственной продукции. Так, в 2012 г. было экспортировано более 20 млн т зерна (около 30 \% его валового сбора), а пшеницы - почти 12 млн т (31% ). Естественно, кто занимается экспортом, получают от этого огромные прибыли и своего места на рынке никому не уступят.

Экспортированный путь развития порождает одну из серьезнейших угроз продовольственной безопасности страны, выраженную в захвате национального зернового рынка иностранными компаниями: контроль рынка в современных условиях тождественен контролю сельского хозяйства в целом [10]. Утверждается, что «в условиях серьезных колебаний валовых сборов зерна его экспорт является оптимальным, самым выгодным способом «санации излишков» (использование того, что превышает внутренние потребности). При этом рынок, мол, - «избыточное» производство зерна, с одной стороны, является условием стабильности внутреннего рынка и страховкой от неурожая; с другой стороны, перепроизводство зерна грозит обрушением цен, чреватым разорением сельхозтоваропроизводителей. Отсюда и необходимость господдержки зернового экспорта, т. е. «экспорт - это не цель, а средство поддержки отечественного производителя» [11]. Россия находится на третьем месте (после США и Евросоюза) по экспорту зерновых, в то же время импортирует незначительное количество высококачественного зерна (около 1 \% от общего объема сбора). Общее потребление России составляет 32 млн т зерна в год. При урожае всех зерновых в России в 2013 г. (91 млн т) очевидно, что продовольственная безопасность России по зерну обеспечена с запасом.

В Доктрине продовольственной безопасности РФ определено, что наращивание экспорта сельскохозяйственной продукции, сырья и продовольствия возможно только по мере насыщения ими внутреннего рынка ${ }^{2}$. Продолжается постепенное снижение зависимости внутреннего рынка РФ от импорта основных видов сельскохозяйственной продукции и продовольствия. По данным Министерства сельского хозяйства РФ, импорт товаров агропромышленного комплекса в 2012 г. уменьшился на 5,5 \% до 40,2 млрд дол., а экспорт возрос на 24,5 \% до 16,6 млрд дол.

Как показывают данные ${ }^{3}$, импортные поставки продовольствия устойчиво занимают свыше четверти национального потребительского рынка. Для России, как и для других стран с трансформируемой экономикой, импорт играет определенную положительную роль в формировании рыночных отношений в аграрной сфере, способствуя развитию конкуренции на внутреннем продовольственном рынке. Исходя из изложенного, можно сделать вывод, что обеспечение продовольственной безопасности является приоритетным направлением государственной политики, так как охватывает широкий спектр национальных, экономических, социальных, демографических и экологических факторов.

Вступление России во Всемирную торговую организацию практически дает «зеленый свет» для скупки российских сельскохозяйственных земель и предприятий агропромышленного сектора крупными иностранными компаниями, имеющими доступ к дешевым кредитным ресурсам международных финансовых институтов. Противостоять их экспансии отечественные производители самостоятельно, без государственной поддержки не смогут, и это не только зафиксировало, но и усугубило текущее положение дел как в самом аграрном секторе, так и в смежных с ним отраслях экономики: производстве удобрений, гербицидов и пестицидов, сельскохозяйственной техники, в пищевой промышленности и т. д. Не говоря уже о «выравнивании» инфраструктурных цен и тарифов со «среднемировыми» показателями и

\footnotetext{
${ }^{2}$ Доктрина продовольственной безопасности Российской Федерации.

${ }_{3}$ Федеральная служба государственной статистики [Электронный ресурс]: офиц. сайт. URL: www.gks.ru.
}

\section{Baikal Research Journal}


критическом сокращении размеров господдержки национального сельского хозяйства, включая налоговые льготы [12].

Несмотря на кризисное урезание бюджетных расходов, сельское хозяйство РФ единственная сфера, для которой финансирование не снизили, а повысили. В 2015 г. на развитие агропромышленного комплекса было дополнительно направлено 54 млрд р. На ускорение импортзамещения в 2019-2020 гг. выделят более 0,5 трлн р. ${ }^{4}$

Чтобы устранить угрозу продовольственной безопасности РФ, необходимо устранить ряд проблем:

1. Существенно изменить финансовую (в том числе налоговую и кредитную) политику сельскохозяйственного производства и связанных с ним отраслей национальной экономики.

2. Провести ренационализацию земли Российской Федерации как основы существования и развития государства. Усовершенствовать законодательство об отчуждении и национализации неиспользованных сельскохозяйственных земель. Внедрить новый земельный кадастр.

3. Существенно ужесточить требования к качеству импортируемого продовольствия, в частности, к содержанию в нем вредных и опасных для здоровья человека химических и биогенетических компонентов.

\section{Список использованной литературы}

1. Назарчук А. АПК на современном этапе экономической реформы: о концепции аграрной политики и продовольственного обеспечения Российской Федерации / А. Назарчук // Экономист. - 2009. - № 5. - С. 34-44.

2. Климова Н. В. Продовольственная безопасность в обеспечении конкурентоспособности страны [Электронный ресурс] / Н. В. Климова. - Режим доступа: http://econf.rae.ru/ article/6075.

3. Дёмин С. Ю. К проблеме продовольственной безопасности и импортзамещение продовольствия в России / С. Ю. Дёмин // Социально-экономическое развитие России и Монголии: проблемы и перспективы : IV Междунар. науч.-практ. конф. Улан-Батор, 12-15 мая 2015 г. - Улан-Батор : Вост.-Сиб. гос. ун-т технологий и управления, 2015. - C. 111-115.

4. Красильникова Л. Е. К вопросу о продовольственной безопасности России / Л. Е. Красильникова / Экономика и управление: анализ тенденций и перспектив развития. - 2014. Вып. 13. - С. 154-161.

5. Барсукова С. Ю. Индивидуальный исследовательский проект № 08.01.0052 «Формальные и неформальные инструменты защиты отечественного аграрного комплекса: формирование политики «нового протекционизма» [Электронный ресурс] / С. Ю. Барсукова. - Режим доступа: www.aqro-expert.ru/zerno.htm.

6. Красильникова Л. Е. Механизм и инструменты устойчивого развития АПК региона в конкурентной среде / Л. Е. Красильникова, К. А. Миков, А. Н. Пыткин. - Екатеринбург : Ин-т экономики Урал. отд-ния РАН, 2013. - 160 с.

7. О продовольственной безопасности России: докл. группы экспертов Избор. клуба под рук. акад. РАН С. Ю. Глазьева // Изборский клуб. - 2013. - № 7. - С. $42-64$.

8. Внешняя торговля РФ: учеб. пособие / под ред. В. Н. Бурмистрова. - М. : Юристь, 2001. $-384 \mathrm{c}$.

9. Чеботарева М. С. Продовольственная безопасность в России и мире: сущность и проблемы / М. С. Чеботарева // Молодой ученый. — 2012. — № 8. — С. 149-151.

10. Шагайда Н. И. Продовольственная безопасность в России: мониторинг, тенденции и угрозы / Н. И. Шагайда, В. Я. Узун. - М. : Дело : Рос. акад. нар. хоз-ва и гос. службы при Президенте РФ, 2015. - 110 с. - (Научные доклады: экономика).

11. Климова Н. В. Продовольственная безопасность - основа обеспечения безопасности региона / Н. В. Климова // Фундаментальные исследования. - 2012. - № 9-1. - С. 214-219.

12. Сафин Ш. Т. Современное состояние продовольственной безопасности Российской Федерации / Ш. Т. Сафин // Управление инновационным развитием экономики: теория, методология, практика : сб. науч. тр. - Челябинск : Челяб. фил. Финуниверситета, 2014. - 233 с.

\footnotetext{
${ }^{4}$ Министерство сельского хозяйства России [Электронный ресурc] : офиц. сайт. URL : www.mcx.ru.
}

\section{Baikal Research Journal}




\section{References}

1. Nazarchuk A. Agricultural sector at the present stage of economic reform: on concept of agrarian policy and food supply of the Russian Federation Ekonomist = The Economist, 2009, no. 5, pp. 34-44. (In Russian).

2. Klimova N. V. Prodovol'stvennaya bezopasnost'v obespechenii konkurentosposobnosti stra$n y$ [Food security in providing country's competitiveness Available at: http://econf.rae.ru/article/6075. (In Russian).

3. Demin S. Y. On problem of food security and import substitution of food in Russia. Sotsial'no-ekonomicheskoe razvitie Rossii i Mongolii: problemy i perspektivy. IV Mezhdunarodnaya nauchno-prakticheskaya konfernetsiya. Ulan-Bator, 12-15 [Socio-economic development of Russia and Mongolia: problems and prospects. Materials of the 4 th International Science and Practice Conference, Ulan-Bator, May 12-15, 2015]. Eastern Siberian State University of Technology and Management Publ., 2015, pp. 111-115. (In Russian).

4. Krasil'nikova L. E. On issue of Russia's food security. Ekonomika i upravlenie: analiz tendentsii i perspektiv razvitiya = Economics and Management: Analysis of Trends and Development Prospects, 2014, iss. 13, pp. 154-161. (In Russian).

5. Barsukova S. Yu. Individual'nyi issledovatel'skii proekt № 08.01 .0052 «Formal'nye i neformal'nye instrumenty zashchity otechestvennogo agrarnogo kompleksa: formirovanie politiki «novogo protektsionizma» [Individual research project № 08.01 .0052 «Formal and informal tools of protecting national agricultural complex: development policy of «new protectionism»]. Available at: www.aqro-expert.ru/zerno.htm. (In Russian).

6. Krasilnikova L. E., Mikov K. A., Pytkin A. N. Mekhanizm i instrumenty ustoichivogo raz vitiya APK regiona $v$ konkurentnoi srede [Mechanisms and tools of sustainable development of regional agricultural complex in competitive environment]. Ekaterinburg, Institute of Economic, The Ural Branch of Russian Academy of Sciences Publ., 2013. 160 p.

7. Glazyev S. Yu. (ed.). On food security of Russia. Izborskii klub =Izborsk Club, 2013, no. 7, pp. 42-64. (In Russian).

8. Burmistrov. V. N. (ed.). Vneshnyaya torgovlya RF [Foreign trade of the Russian Federation]. Moscow, Yurist' Publ., 2001. 384 p.

9. Chebotareva M. S. Food security in Russia and in the world: essence and problems. Molodoi uchenyi=Young Scientist, 2012, no. 8, pp. 149-151. (In Russian).

10. Shagaida N. I., Uzun V. Ya. Prodovol'stvennaya bezopasnost' $v$ Rossii: monitoring, tendentsii i ugrozy [Food security in Russia: monitoring, trends and threats]. Moscow, Delo Publ., Russian Presidential Academy of National Economy and Public Administration Publ., 2015. 110 p.

11. Klimova N. V. Food security is the basis of providing regional security. Fundamental'nye issledovaniya $=$ Fundamental Research, 2012, no. 9-1, pp. 214-219. (In Russian).

12. Klimova N. V. Current state of food security in the Russian Federation. Upravlenie innovatsionnym razvitiem ekonomiki: teoriya, metodologiya, praktika [Managing innovative development of economy: theory, methodology, practice]. Chelyabinsk branch of Financial University under the Government of the Russian Federation Publ., 2014. 233 p. (In Russian).

\section{Информация об авторе}

Дёмин Сергей Юрьевич - кандидат экономических наук, доцент, кафедра менеджмента, маркетинга и сервиса, Байкальский государственный университет, 664003, г. Иркутск, ул. Ленина, 11, e-mail: demin@isea.ru.

\section{Author}

Sergey Yu. Demin - PhD in Economics, Associate Professor, Chair of Management, Marketing and Services, Baikal State University, 11 Lenin St., 664003, Irkutsk, Russian Federation; e-mail: demin@isea.ru.

\section{Библиографическое описание статьи}

Дёмин С. Ю. Роль импортозамещения в обеспечении продовольственной безопасности в России / С. Ю. Дёмин / / Baikal Research Journal. — 2016. — T. 7, № 2. — DOI : 10.17150/24116262.2016.7(2).10.

\section{Reference to article}

Demin S. Yu. Role of import substitution in providing food security in Russia. Baikal Research Journal, 2016, vol. 7, no. 2. DOI: 10.17150/2411-6262.2016.7(2).10. (In Russian).

\section{Baikal Research Journal}

